\title{
Pressure-dependent inverse bicontinuous cubic phase formation in a phosphatidylinositol 4-phosphate/phosphatidylcholine system
}

\author{
Samuel Furse*,a, b, Nicholas J. Brooks ${ }^{a, b}$, Rüdiger Woscholski ${ }^{a, c}$, Piers R. J. Gaffney ${ }^{a}$, Richard H. \\ Templer ${ }^{\mathrm{a}, \mathrm{b}}$ \\ ${ }^{a}$ Institute of Chemical Biology, Imperial College London, South Kensington Campus, London SW7 2AZ, U.K. \\ ${ }^{b}$ Membrane Biophysics Platform, Department of Chemistry, Imperial College London, South Kensington Campus, London SW7 \\ 2AZ, U.K. \\ ${ }^{c}$ Division of Molecular Biology, Imperial College London, South Kensington Campus, London SW7 2AZ, U.K. \\ ${ }_{10}^{*}$ Present address: Molekylærbiologisk institutt, Unveristetet i Bergen, Thormøhlens gate 55, 5020-Bergen, Norway. E-mail for \\ correspondence: samuel.furse@uib.no, samuel@samuelfurse.com.
}

\begin{abstract}
In this paper, we report the inositide-driven formation of an inverse bicontinuous cubic phase with space is group la3d ( $Q_{\| I}{ }^{G}$, gyroid phase). The system under study consisted of distearoylphosphatidylinositol 4phosphate (DSPIP) and dioleoylphosphatidylcholine at a molar ratio of 1:49, with a physiological

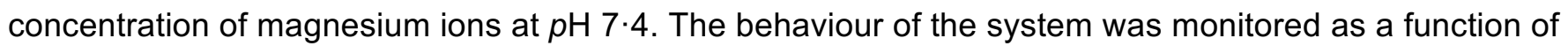
temperature and pressure. The formation of the phase with la3d geometry was recorded repeatably at high pressure, and occurred more readily at higher temperatures. We conclude that the la3d phase formed is a ${ }_{20}$ thermodynamically stable structure, and that DSPIP is a potent source of membrane curvature that can drive the formation of mesophases with both 2- and 3D geometry.
\end{abstract}

\section{Key words}

Phosphatidylinositol 4-phosphate, X-ray diffraction, curvature elastic stress, inverse cubic phase, ${ }_{25}$ hydrostatic pressure.

\section{Abbreviations}

Dioleoylphosphatidylcholine, DOPC; distearoylphosphatidylinositol 4-phosphate, DSPIP; Inverse hexagonal, $\mathrm{H}_{\|}$; multi-lamellar vesicle, MLV; Phosphatidylinositol 4-phosphate, PI-4-P.

\section{Specifications Table}

\begin{tabular}{|l|l|}
\hline Subject area & Chemical biology, Physical Chemistry \\
\hline Compounds & $\begin{array}{l}\text { Distearoyl-phosphatidylinositol 4-phosphate, dioleoyl } \\
\text { phosphatidylcholine }\end{array}$ \\
\hline Data category & Physicochemical, biophysical \\
\hline Data acquisition format & X-ray diffraction \\
\hline Data type & Analysed \\
\hline Procedure & $\begin{array}{l}\text { Temperature and pressure scans of hydrated lipid mixture as a model } \\
\text { for a biological membrane }\end{array}$ \\
\hline Data accessibility & Data is in this article. \\
\hline
\end{tabular}

\section{Rationale}

Research interest in lipid aggregations with cubic geometry has increased in recent years, owing to suggestions that swollen cubic phases are a model for the membrane division events observed in vivo. Such events include endocytosis [1-3], vesicle formation[4, 5] and vesicle trafficking [6]. Work on model lipid systems has provided evidence for induction of vesicle budding with changes ${ }_{40}$ in buffer[7] and for cubic phases that are hydration-dependent [8] and tuneable with respect to pressure $[9,10]$. The appearance in model systems of lipid aggregations of dimensions and deometrv similar to those in nature. but with non-natural linid mixtures. led us to the hvoothesis 
that naturally-occurring lipid isoforms of certain lipids may effect the same shifts in model systems under application of hydrostatic pressure.

${ }_{45}$ Recent reports have provided evidence that the inositide group of phospholipids (also known as phosphatidylinositol- or PI lipids) can drive the formation of curved lipid aggregations [11, 12]. These physical observations may be very significant in interpreting cellular levels of inositides during processes involving the generation of membrane curvature, such as cytokinesis in HeLa cells[13] and endocytotic processes in pollen[14]. The evidence surrounding the physical ${ }_{50}$ behaviour of inositides has led to suggestions[15] that their physical role(s) may be as significant as their well-established signalling ones[16-18]. This body of work led us to explore the phase behaviour of a typically lamellar system that had been doped with a PI-4-P.

\section{Procedure}

${ }_{5}$ DOPC was obtained from Avanti Polar Lipids (Alabaster, AL) and used without further purification. All salts, solvents and buffers were obtained from Sigma Aldrich (St. Louis, MO). Racemic DSPIP was prepared in our laboratory [19, 20], as its bis-ammonium salt.

\section{Sample Preparation and Equilibration}

All samples were prepared by dissolving the lipids in $\mathrm{CHCl}_{3}: \mathrm{CH}_{3} \mathrm{OH}: \mathrm{H}_{2} \mathrm{O}$ (7:2:0.1). These were ${ }_{60}$ then mixed in the required molar ratios, the resulting mixtures were then frozen using liquid nitrogen and freeze-dried over a $48 \mathrm{~h}$ period to ensure that all solvent was removed from the sample. Approximately $3 \mathrm{mg}$ of lipid was added to an X-ray capillary (Gulmay Medical Ltd, UK, $1.5 \mathrm{~mm}$ ) and hydrated with $66 \% \mathrm{wt} / \mathrm{wt}$ buffer. The buffer used for sample hydration contained 5 $\mathrm{mM} \mathrm{MgCl} 2$ and $20 \mathrm{mM}$ Tris-base adjusted to $\mathrm{pH} 7.4$ at $25^{\circ} \mathrm{C}$. The glass capillaries were flame ${ }_{65}$ sealed, and then sealed with silicone sealant (Dow Corning Corp) to maintain a fixed hydration level. The uncertainty in the concentration $\Delta \mathrm{c} / \mathrm{c}$ has been estimated to be $1-2 \mathrm{wt} \%$. The sample was allowed to equilibrate for 7 days at $25^{\circ} \mathrm{C}$ before use. The weight of the sealed capillary before and after each X-ray diffraction experiment was noted and compared to the initial tare, with no water loss observed. Samples were equilibrated in the synchrotron for 15 minutes at each ${ }_{70}$ temperature before acquisition, and for 10 minutes before acquisition at each pressure, in agreement with previous studies[11, 12].

\section{X-Ray Instrumentation}

Synchrotron small-angle X-ray scattering (SAXS) measurements were carried out at the ID02 high brilliance beamline at the European Synchrotron Radiation Facility (ESRF) in Grenoble (France), ${ }_{5}$ using a custom-built high pressure sample cell capable of applying hydrostatic pressures of between 1 and 4000 bar to the sample, with an accuracy of \pm 10 Bar. This apparatus was designed, built and generously provided by Professor R. Winter, University of Dortmund, and is described in detail by Woenckhaus et al.[21]. The temperature of the high pressure cell was controlled with a precision of $\pm 0.2^{\circ} \mathrm{C}$ by means of a thermostat jacket through which water was ${ }_{80}$ circulated continuously. The synchrotron beam line was tuned to deliver a photon energy of $16.5 \mathrm{keV}$ (corresponding to a wavelength of $0.7515 \AA$ ), with beam dimensions of approximately $200 \times 400 \mu \mathrm{m}$ and a typical flux of $3 \times 10^{13}$ photons/s. Diffraction patterns were recorded using a fibre-optically coupled FReLoN (Fast-Readout, Low Noise) CCD detector, with a sample-detector distance of $2.5 \mathrm{~m}$. The 2-D images were converted to 1-D patterns and subsequently analysed ${ }_{85}$ using AXcess, an in-house developed software package written by Dr Andrew Heron [22] using the IDL programming environment. 


\section{Data, value and validation}

In order to explore the potential for inositides to induce membrane curvature, we have studied a lipid mixture comprising distearoyl phosphatidylinositol 4-phosphate (DSPIP, a PI-4-P) and dioleoylphosphatidylcholine (DOPC) (molar ratio 1:49) as a function of pressure and temperature.

os This binary system was hydrated using excess buffer ( $5 \mathrm{mM} \mathrm{MgCl}_{2}$ and $20 \mathrm{mM}$ Tris-base, adjusted to $\mathrm{pH} 7 \cdot 4$ at $25^{\circ} \mathrm{C}$ ). Both the proportion of DSPIP and the magnesium concentration are typical of those found in biological systems [23-26].

We found that above 700 Bar and $33.4{ }^{\circ} \mathrm{C}$ this binary system began to display reflections consistent with a gyroid cubic phase of space group la3d, alongside a fluid lamellar phase. Only io from $43.0^{\circ} \mathrm{C}$ were three diffraction reflections clearly visible (Figure 1), allowing clear identification of the geometry of the phase at this point. At lower pressures, this system exhibits an inverse hexagonal phase, as previously reported [27] (Figure 2). Importantly, cubic phases are not observed in fully hydrated systems containing only DOPC [28].

At $43{ }^{\circ} \mathrm{C}$, as the pressure is increased, both the lamellar and cubic phases form simultaneously ${ }_{105}$ at 1000 bar and there is a region of coexistence between these with the $H_{\|}$phase up to 1800 bar (Figure 2). According to the Gibb's phase rule, only two structures should coexist at equilibrium as the system is hydrated in excess buffer. We therefore suggest that the three-phase coexistence observed here is due to slow transition kinetics. The time taken to change the pressure at each point, and equilibrate, means that the co-existence lasts about an hour.

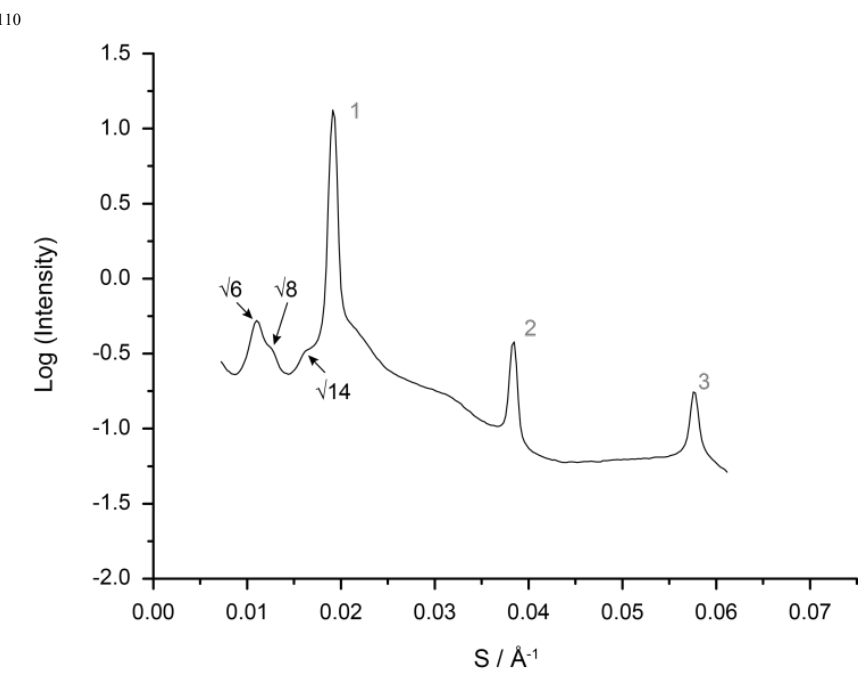

Figure 1. SAXS pattern from the fluid lamellar (peaks with position ratio 1:2:3) and inverse la3d cubic phase (peaks with position ratio $\sqrt{6}: \sqrt{8}: \sqrt{14})$ observed in hydrated $2 \mathrm{~mol} \%$ DSPIP in DOPC at 3000 bar and $43.0^{\circ} \mathrm{C}$.

The diffracted intensity from the cubic phase is clearly less than from the lamellar phase. However, this smaller intensity from the cubic phase is consistent with other reports in which coexistence of lamellar and cubic phases is thought to be due to the formation of multi-lamellar 'onion' vesicles (MLVs)[29-31] in which much less of the sample must adopt a cubic phase than the lamellar structure. 


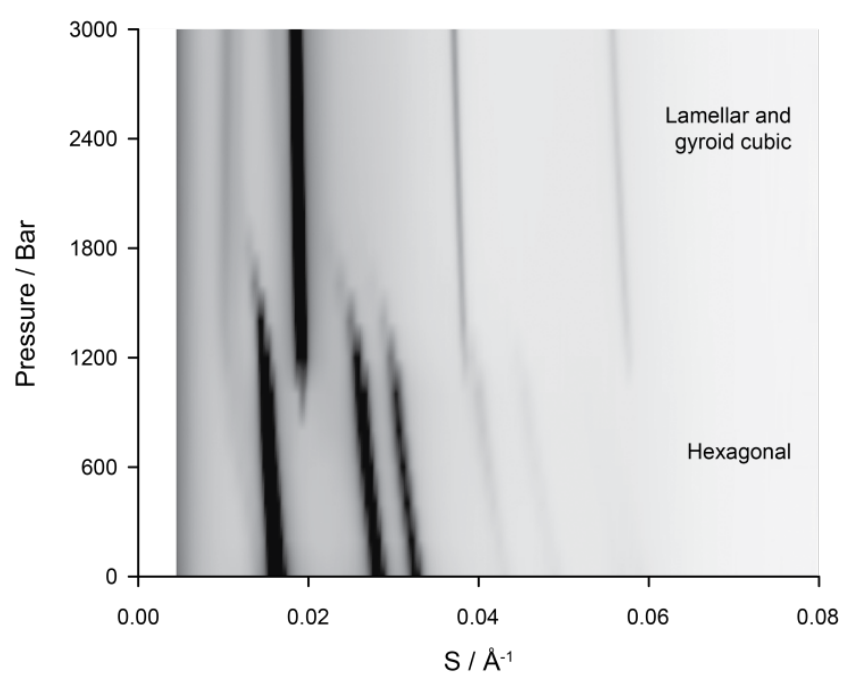

Figure 2. Stacked diffraction plots with increasing pressure from atmospheric pressure to 3000 bar for 2 mol \% DSPIP in DOPC at $43.0^{\circ} \mathrm{C}$. The mixture adopts an inverse hexagonal phase from atmospheric pressure to 1000 bar and transforms to coexisting, gyroid inverse bicontinuous cubic and fluid lamellar phases at higher pressures via a 3 phase ${ }_{25}$ coexistence region.

Interestingly, the cubic phase is only formed in this system in co-existence with a fluid lamellar phase. At $24.0^{\circ} \mathrm{C}$ and 2300 bar this system forms a single crystalline lamellar phase [27], something not consistent with the reported behaviour of pure DOPC at this temperature and ${ }_{130}$ pressure [32]. This suggests that the PI-4-P component remains mixed with DOPC both under these conditions and those where a single hexagonal phase is formed. However it is unclear if the coexisting fluid lamellar and cubic phases have the same lipid composition.

The observation here of two coexisting phases of different curvature (the cubic and lamellar phases) in a system composed of two lipids with different curvature properties may indicate that in the two phases have different lipid compositions. The coexisting lamellar and cubic phases transform from a single inverse hexagonal phase in a pressure-dependent manner and are stable over a range of temperatures and pressures. Additionally, the hexagonal phase is reformed on lowering the pressure suggesting that all these phases are thermodynamically stable structures, albeit perhaps arising through slow transition kinetics (3 phase region lasts for $\sim 60$ min, 10001800 Bar).

MLVs, in which a nucleus of a cubic phase is surrounded by lamellar bilayers, have also been recorded at equilibrium [29-31]. To date, the space group of the cubic phase observed in these vesicles has either been $\mathrm{Pn} 3 \mathrm{~m}$ [29] or $\operatorname{Im} 3 \mathrm{~m}[30,31]$ and it is noteworthy that in this study, we observe an cubic phase with la3d geometry. The cubic phase here also has a rather high lattice ${ }_{145}$ parameter $(210-240$ Å, Figure 3).

The formation of an inverse bicontinuous cubic phase and inverse hexagonal phase in a phosphatidylcholine-rich system by low concentration of an inositide demonstrates that this class of lipid is a potent source of curvature $[11,12,33]$. The gyroid bicontinuous cubic phase tends to be observed for longer chain-length systems with relatively low packing stress [31], and can ${ }_{150}$ formed on reduction of the packing stress of diamond cubic systems [31, 34]. Further work is required to establish the character of bicontinuous cubic phases with large $d$-spacings that are exhibited by naturally-occurring lipids and what role these may play in vivo. 


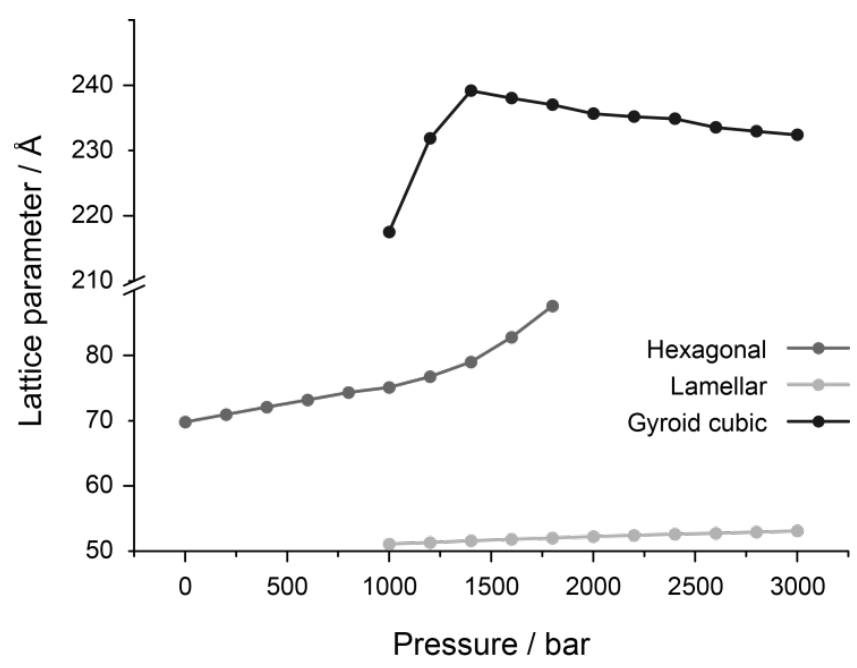

${ }_{155}$ Figure 3. Changes in d-spacing of the phases observed as a function of pressure in $2 \mathrm{~mol} \%$ DSPIP at $43.0^{\circ} \mathrm{C}$.

\section{Acknowledgements}

SF would like to thank $\mathrm{Dr}$ O. Ces and G. C. Shearman for excellent guidance, support and helpful ${ }_{160}$ discussions. This work was supported by ESPRC Platform grant GR/S77721, BBSRC Grant BB/F013167/1 and by an EPSRC Centre for Doctoral Training Studentship from the Institute of Chemical Biology (Imperial College London) awarded to SF. We acknowledge the European Synchrotron Radiation Facility (Grenoble, France) for the provision of synchrotron radiation facilities and we would like to thank Dr Pierre Panine for assistance in using beam line ID02.

\section{Author contributions}

The experimental work was designed and carried out by SF and NJB, and supervised by RHT. RW, RHT and PRJG conceived the research project and wrote the grant application. The manuscript was written by SF and NJB. All authors commented on the manuscript and approved ${ }_{100}$ its final form.

\section{References}

[1] G. Di Paolo, P. De Camilli, Nature, 443 (2006) 651-657.

[2] S.A. Mousavi, L. Malerod, T. Berg, R. Kjeken, Biochem. J., 377 (2004 ) 1-16.

175 [3] Y. Zhao, A. Yan, J.A. Feijo, M. Furutani, T. Takenawa, I. Hwang, Y. Fu, Z.B. Yang, Plant Cell, 22 (2010) $4031-4044$.

[4] A. Lorente-Rodriguez, C. Barlowe, Molecular Biology of the Cell, 22 (2010) 216-229.

[5] J. He, J.L. Scott, A. Heroux, S. Roy, M. Lenoir, M. Overduin, R.V. Stahelin, T.G. Kutateladze, Journal of Biological Chemistry, 286 (2011) 18650-18657.

[6] S. Minogue, K.M.E. Chu, E.J. Westover, D.F. Covey, J.J. Hsuan, M.G. Waugh, Journal of Lipid Research, 51 (2010) $2314-2324$.

180 [7] H.M.G. Barriga, R. Bazin, R.H. Templer, R.V. Law, O. Ces, Langmuir, (2015).

[8] T.Y.D. Tang, N.J. Brooks, O. Ces, J.M. Seddon, R.H. Templer, Soft Matter, 11 (2015) 1991-1997.

[9] H.M.G. Barriga, A.I.I. Tyler, N.L.C. McCarthy, E.S. Parsons, O. Ces, R.V. Law, J.M. Seddon, N.J. Brooks, Soft Matter, 11 (2015) 600-607.

[10] A.I.I. Tyler, H.M.G. Barriga, E.S. Parsons, N.L.C. McCarthy, O. Ces, R.V. Law, J.M. Seddon, N.J. Brooks, Soft Matter, 11 185 (2015) 3279-3286.

[11] X. Mulet, R.H. Templer, R. Woscholski, O. Ces, Langmuir, 24 (2008) 8443-8447.

[12] S. Furse, N.J. Brooks, A.M. Seddon, R. Woscholski, R.H. Templer, E.W. Tate, P.R.J. Gaffney, O. Ces, Soft Matter, 8 (2012) 3090-3093.

[13] G.E. Atilla-Gokcumen, E. Muro, J. Relat-Goberna, S. Sasse, A. Bedigian, Margaret L. Coughlin, S. Garcia-Manyes, Ulrike S. 190 Eggert, Cell, 156 (2014) 428-439.

[14] Y. Zhao, A. Yan, J.A. Feijó, M. Furutani, T. Takenawa, I. Hwang, Y. Fu, Z. Yang, The Plant Cell Online, 22 (2010) $4031-4044$.

[15] S. Furse, Journal of Chemical Biology, 8 (2015) 1-3.

[16] M.J. Berridge, Biochemical Journal, 220 (1984) 345-360.

[17] M.J. Berridge, R.F. Irvine, Nature, 312 (1984) 315-321.

195 [18] M.J. Berridge, R.F. Irvine, Nature, 341 (1989) 197-205

[19] S. Furse, in: Institute of Chemical Biology, Imperial College London, Imperial College, London, British Library, Imperial College Library, 2011, pp. 445.

[20] S. Furse, L. Mak, E.W. Tate, R.H. Templer, O. Ces, R. Woscholski, P.R.J. Gaffney, Org. Biomol. Chem., 13 (2015) $2001-2011$.

[21] J. Woenckhaus, R. Kohling, R. Winter, P. Thiyagarajan, S. Finet, Rev. Sci. Instrum., 71 (2000) 3895-3899. 
${ }_{200}$ [22] J.M. Seddon, A.M. Squires, C.E. Conn, O. Ces, A.J. Heron, X. Mulet, G.C. Shearman, R.H. Templer, Philosophical Transactions of the Royal Society A: Mathematical, Physical and Engineering Sciences, 364 (2006) 2635-2655.

[23] S. Bodin, S. Giuriato, J. Ragab, B.M. Humbel, C. Viala, C. Vieu, H. Chap, B. Payrastre, Biochemistry, 40 (2001) $15290-15299$.

[24] R.J. Botelho, M. Teruel, R. Dierckman, R. Anderson, A. Wells, J.D. York, T. Meyer, S. Grinstein, Journal of Cell Biology, 151 (2000) 1353-1367.

205 [25] D.J. Gillooly, C. Raiborg, H. Stenmark, Histochemistry and Cell Biology, 120 (2003) 445-453.

[26] M.M. Hill, J.H. Feng, B.A. Hemmings, Current Biology, 12 (2002) 1251-1255.

[27] S. Furse, N.J. Brooks, A.M. Seddon, R. Woscholski, R.H. Templer, E.W. Tate, P.R.J. Gaffney, O. Ces, Soft Matter, 8 (2012) 3090-3093.

[28] R. Koynova, M. Caffrey, Biochim et Biophys Acta - Rev on Biomem, 1376 (1998) 91-145.

210 [29] C.E. Conn, O. Ces, X. Mulet, S. Finet, R. Winter, J.M. Seddon, R.H. Templer, Physical Review Letters, 96 (2006) 108102.

[30] O. Diat, D. Roux, F. Nallet, J. Phys. II France, 3 (1993) 1427-1452.

[31] G.C. Shearman, B.J. Khoo, M.-L. Motherwell, K.A. Brakke, O. Ces, C.E. Conn, J.M. Seddon, R.H. Templer, Langmuir, 23 (2007) 7276-7285.

[32] A. Landwehr, R. Winter, Ber. Bunseges. Phys. Chem., 98 (1994) 214-218.

215 [33] R. Koynova, M. Caffrey, Biochimica et Biophysica Acta (BBA) - Reviews on Biomembranes, 1376 (1998) 91-145.

[34] T. Oka, Langmuir, 31 (2015) 3180-3185. 